\title{
A Digital-First Model of Diabetes Care
}

\author{
Joseph A. Cafazzo, PhD, PEng ${ }^{1-3}$
}

\begin{abstract}
If we were to create the diabetes care experience anew, there is little doubt that it would not resemble the current bricks-and-mortar way we do things currently. For however a future model of care is designed, it would assume a digital-first approach, whereby the modern conveniences of digitally-mediated services we have experienced in other industries would be reflected in our diabetes care. To this end, our diabetes data would be liberated, transparent to those that need it, but safe and secure otherwise. We would have access to new tools that create insights that lower the burden, not add to it. And access to care would be just in time, convenient, and from a distance when needed. What is stopping a digital-first model is complex and deeply seated, but not insurmountable with engagement from industry, regulators, and care providers that are all willing to modernize the way care is delivered. Personal human interaction will continue to play an important part in the care for millions of people living with diabetes, no matter the sophistication of these digital services. What these technologies will provide is the human capacity to deal with the higher need, vulnerable people for whom access to timely care is an issue. Moreover, it will provide choice for an increasingly diverse population that seeks options for the form, and the delivery, of their personalized care.
\end{abstract}

Keywords: Diabetes, Mobile applications, Behavior adherence, Self-management, mHealth, eHealth.

\section{Introduction}

W E ARE NOW more than a decade beyond the introduction of the "app" on your mobile phone, popularized by the iPhone and Android-based smartphones. The phenomenon of mobile phone apps created a flurry of development for all sorts of health and wellness conditions, with thousands of apps created for weight loss, exercise, and of course diabetes. It was no surprise that diabetes was the one chronic disease to receive the most attention from technology companies. ${ }^{1}$ Hundreds of diabetes applications have been produced that are available for free, for a small fee, or as a monthly subscription. ${ }^{2}$ Given the need for regular tracking of quantitative data, such as blood glucose, carbohydrate intake, dosing of insulin, as well as other data points such as exercise, sleep, and other factors that can affect glycemic control, diabetes is perhaps the most amenable of the chronic conditions to the use of mobile computational device.

In addition to the ability of apps to deal with these quantitative aspects of diabetes management, the mobility cap- abilities also lend themselves well to the free-living behavioral aspects. So many of the challenges of managing diabetes occur in the moments of everyday life, not in the physician's office or with an educator, where the help typically lies. Having a common ubiquitous personal device on hand, which happens to double as an aid for your diabetes: to measure, to advise, to connect with others, and yes, to nudge you toward better health behaviors in those most opportune times of one's day, is a remarkable innovation.

That is, potentially.

There have been dozens of companies formed in recent years to create digital platforms to facilitate new forms of diabetes care, but the uptake by patients and their providers has been the exception and not the norm. This article aims to reflect on a decade of digital health interventions: their potential, their pitfalls, and their barriers to use in a health system that is slow to change despite rapid technological advancement. Examined here is the case that any discussion of the use of digital health in diabetes must examine the very nature of how care is delivered, and to reconsider the past

\footnotetext{
${ }^{1}$ Centre for Global eHealth Innovation, and the Wolfond Chair in Digital Health, Techna Institute, University Health Network, Toronto, Ontario, Canada.

${ }^{2}$ Institute of Health Policy Management and Evaluation, Dalla Lana School of Public Health, Toronto, Ontario, Canada.

${ }^{3}$ Institute of Biomaterials and Biomedical Engineering, University of Toronto, Toronto, Ontario, Canada.
} 
models that cannot meet demand and the quality of care that people living with diabetes expect.

\section{Evidence and Excuses}

The reality of the use of apps is that despite the level of interest, investment, and stated propensity, the level of uptake has not been very high, in particular, for those living with type 2 diabetes (T2D). ${ }^{3,4}$ The most widely suggested reason is that without evidence to support their use, there will be only sporadic nonsystemic adoption of these interventions.

There have, however, been a series of systematic reviews and meta-analyses published recently of trials of increasingly higher quality. ${ }^{5-10}$ These analyses indicate that there have been more than a dozen randomized controlled trials (RCTs) of digital health interventions for diabetes in the past decade. These reviews generally suggest that they are more effective in improving glycemic control with those living with T2D than those with type 1 diabetes. The clinical outcome indicates reductions in hemoglobin $\mathrm{A} 1 \mathrm{C}(\mathrm{HbA} 1 \mathrm{c})$ with means and ranges of $0.44 \%,{ }^{8} 0.49 \%,{ }^{10} 0.67 \%,{ }^{5} 0.8 \%,{ }^{6} 0.1 \%-0.8 \%,{ }^{7}$ and $0.15 \%-1.9 \%$. ${ }^{9}$

Although the reported reductions were small and may be considered clinically insignificant in some cases, the results were always consistent in lowering HbA1c. This is an especially important finding in that these trials were, in many cases, the first generation versions of the interventions, and did not have the benefit of the learnings from any previous literature on user needs, specifications, design, development, or implementation of what can be a complex sociotechnical intervention. Many of these early apps were plagued with poor usability that caused attrition. ${ }^{1,9,11-13}$ Others were simply deemed not beneficial enough for the effort required to use them.

Further complicating their evaluation is the considerable heterogeneity in the various diabetes apps designs and implementation tactics. To address this, there has been analysis conducted on the taxonomy of common features and attributes that make these interventions more effective. In particular, the ability to receive timely contextualized feedback from personally generated data is associated with improvements in HbAlc. ${ }^{7}$ A recent systematic review by Greenwood et al. found that the positive impact of diabetes app use was further enhanced when facilitated through a care provider. ${ }^{7}$ The more successful trials demonstrated that app use enhanced the ability to elicit improved self-care skills and self-confidence and in lowering the fear of dealing with potentially life-threatening episodes of hypoglycemia. ${ }^{8}$ In the future, it is expected that the evaluation of these interventions will move beyond the coarseness of HbA1c as a primary outcome and use more contemporary measures of improved glycemic control. ${ }^{14,15}$

Nevertheless, one would expect that with the rate of the development of these diabetes apps, and the emerging evidence in supporting their use, we would have seen more adoption of these tools, even going as far as considering them a standard of care, prescribed by diabetes caregivers. Strong arguments persist that there is not enough established evidence to support their use, but the suggestion that it is only evidence that is needed for clinical uptake is not true either. ${ }^{16-19}$ Recognizing the inherent limitations of RCTs in assessing the use and efficacy of medications and technologies in every- day life, a growing number of stakeholders (e.g., regulatory agencies, payers, and clinicians) are turning to realworld evidence in conjunction with RCT data. ${ }^{20,21}$ Moreover, much of the current evidence in diabetes is, in fact, much stronger than any link to improved outcomes associated with general health information technologies, such as electronic health records, which inexplicably require little or no return on investment, and appear to be driving physician burnout. $^{22-24}$

\section{A Digital Model of Diabetes Care}

If patients do use an app in their own care, it is often done independently of their care provider, who cannot deal with the rapid pace of the development of apps and the extra data points they can generate. Clinic visits are increasingly short and cannot accommodate the multitude of disparate data sources and the rapidly developing app ecosystem. If care providers are to engage, they need to see a clearer value for themselves beyond any demonstrable improvement in health outcomes. This could come in the form of improved remuneration or improved efficiencies. Hence, it is the existing health system issues that are perhaps the more challenging barriers to greater adoption, suggesting that we need to consider a modernized diabetes care model.

If we were to start again from the beginning in designing a care model for those living with diabetes, it certainly would not be predicated on the infrequent face-to-face episodic care that remains nearly unchanged for decades. In particular, diabetes management is perhaps the least amenable of the chronic conditions to the infrequent and poorly accessible resources that are typical in care interactions. The needs for those living with diabetes are more immediate and tend not to keep until the next scheduled visit when the moment has passed and context often forgotten, leading to a constant inertia in one's care.

Given the technological advances posited by digital health, one could envision a model where care, including treatment, decision support, and education, could be delivered in context and in the moment. More personal interactions with the care provider would be done virtually, informed through a complete, but succinct, relevant data set, which is also in context for the physician, educator, or coach. The more timely feedback and care provision in this arrangement would require a redo of how care providers work, interact, and are even compensated. But it would likely be far more efficient and efficacious than the current clinician-first supply-driven model.

Creating such a model cannot be achieved until some practical problems are solved in terms of digital health literacy and diabetes data interoperability. ${ }^{25,26}$

\section{Why Can't I See My Data?}

Nothing has frustrated the progress of digital health in diabetes more than the entire lack of true interoperability of devices, apps, and clinical information technology systems. The slow progress toward a single view into one's own blood glucose readings, insulin dosing, and other diabetes data in a sharable form for care providers has only been achieved through a patchwork of point-to-point proprietary interfaces, hacks, and closed ecosystems. Whether for 
personal needs, or the clinic, the solutions are a mess of cables and time-consuming workarounds. The end result is often just more work for everyone, and the marginalizing of those who do not have the tech literacy, time, or mindset to jump through hoops to achieve a simple view into their own personal data.

Even for those capable of sitting down with their devices, hooking them up, downloading files, uploading files, and finally viewing their data, this elaborate complex process inevitably leads them to question the value in the long term. As a result, a small minority of providers and patients routinely download and retrospectively view device data, citing a range of reasons including technical issues and cognitive burden. ${ }^{27}$ Moreover, reviewing these data retrospectively and infrequently, does not carry the value it does in the free-living contextualized way that is known to be effective.

In the need for expediency, manufacturers and developers have created a patchwork of software and devices for narrow views onto their own specific data types, where the context is lost. This complexity marginalizes most people living with diabetes who could not contemplate such an effort. ${ }^{3,28}$ There have been a number of efforts for interoperability standards, ${ }^{29-33}$ with uptake for blood glucose monitors being the most well established, but poor uptake among manufacturers of continuous glucose monitoring (CGM) sensors, insulin pens, and pumps.

Unfortunately, there are business reasons for device manufacturers not to be interoperable with third-party devices and software. First, the value of the data generated is not insignificant in the age of analytics and artificial intelligence applications. As well, by allowing a third-party software developer to connect directly, the device manufacturers run the risk of losing their exclusivity to derive intelligence from that customer's use of their product and potentially lose the customer altogether. Instead, the tactic some manufacturers use is to build their own proprietary platform to collect data from their customer's devices, with third-party software access only allowed through the manufacturers' proprietary access scheme, if at all. The result for the end user is to deal with multiple disparate manufacturers' platforms, none of which will serve their needs alone. There are commercial ${ }^{34}$ and open source solutions ${ }^{33}$ that attempt to aggregate these disparate platforms, but it remains only for those willing to put in the time and effort, and who accept the limitation of a retrospective view of their data.

No other innovation has been affected more by this lack of interoperability than what many believe is the panacea of type 1 diabetes management - the artificial pancreas. Perhaps more humbly known as an automated insulin delivery (AID) system, it is the integration of CGM, an insulin pump, and a controller working in concert to achieve optimal glycemic control, with little intervention by the user. ${ }^{35}$ AID systems have made considerable progress in recent years with a thriving do-it-yourself community creating their own systems, achieved through the unconventional means of using older diabetes devices and reverse engineering their means of communication. $^{36,37}$ This occurs while clinicians and regulators watch with concern, but with the reticence that they are not in any position to do any more than advise caution. That said, the regulatory bar is now set for software developers to take on the responsibility for advanced decision support and automated functionality now that there is clearer guidance available for software as a medical device, ${ }^{38,39}$ a streamlined pathway through special controls, ${ }^{40}$ and the FDA Pre-Cert program. ${ }^{41}$ There have been coordinated attempts for regulators, manufacturers, clinicians, with leadership by people with diabetes, to come together to address these thorny issues with some progress, ${ }^{42}$ but far from the progress that could be achieved if there was true interoperability and commitment to true data liberation. ${ }^{29,30}$

For the majority of those living with diabetes, the very tools that were meant to make one's life easier, can create an even greater burden. ${ }^{4,43,44}$ Even if one uses an app in the course of his or her personal management, remaining committed to its use can be difficult, as it may require too much effort, for too few insights, in an untimely way. As such, it may not be the act of intensive self-monitoring of blood glucose itself that may be burdensome. ${ }^{45}$ The developers of these applications need to be aware that they can require too much cognitive effort for one to interpret, and can also bring about feelings of inadequacy and guilt that they are not as well managed as they expect of themselves, or what their caregivers expect of them.

\section{Can You Control What You Do Not Measure?}

The utility of digital health interventions will be limited not only by the lack of data interoperability and the burden that it may invoke but also by the lack of relevant data in the first place. This is no more evident than in the current state of patient-reported data for T2D. The wisdom of monitoring one's own blood glucose in T2D has been questioned for the past decade, whereby researchers and clinicians do not necessarily see the value of self-monitoring in this group if they are not on insulin. ${ }^{46,47}$ In a rush to reduce health costs, payers in the UK and Canada were quick to pounce on the evidence that recommended that costly test strips coverage be reduced or eliminated. ${ }^{48,49}$ These clinical and policy outcomes are perhaps not surprising given the state of typical off-the-shelf blood glucose monitoring. Nearly all of the meters on the market display little more than a single reading, with a lack of context, and nothing that is actionable. The newer meters that provided words of encouragement and simple insights through on-screen messaging have also been shown to be ineffective, further suggesting that it is not a matter of the sophistication of the technology. 50,51

For many, the evidence suggesting that the regular measurement of blood glucose is not needed for self-management is counterintuitive and uninformed. ${ }^{52,53}$ There are also indications that there is a high degree of variability of glycemic response in individuals, suggesting that a more personalized phenotyping and treatment are warranted. ${ }^{54}$ What then are the expectations of someone to self-manage this condition if they have no means to measure the outcome, other than the coarse measurement of HbA1c? How can day-to-day selfmanagement behaviors be related to such an infrequent measure? How, without any cue-to-action, ${ }^{55}$ would anyone act on a condition that is mostly asymptomatic ? ${ }^{56}$

It has been strongly posited that the act of self-monitoring of blood glucose was not beneficial when taken without structured measurements, contextualized readings, and coaching. This body of evidence requires a rethinking of the way SelfMonitoring of Blood Glucose (SMBG) has been used and the perception of its value. ${ }^{57-61}$ Unlike drug trials, the use of 
SMBG is a complex behavioral intervention that is highly dependent on implementation in clinic, and in incorporating it into the day-to-day routine of one living with diabetes. It is clear that without structured testing that SMBG would be of limited value as the critics have stated. Nevertheless, the absence of any form of measurement and self-awareness could easily lead to disengagement and passivity that certainly will not lead to any improvements of glycemic control for this population.

A structured program for SMBG can be difficult and resource intensive to deliver, and recommendations on the proper use are not always followed, ${ }^{7,62}$ hence the poor efficacy results. Digital health interventions have the potential to greatly facilitate a structured testing regimen. Reminders, prompts, challenges, and other behavioral nudges can be employed in such applications. Data collection could be automated, interpreted, and feedback provided, all while limiting the individual burden, if well designed and executed. ${ }^{63}$ Furthermore, the creation and use of a digitally mediated version of the diabetes prevention program (DPP) ${ }^{64}$ suggest that such interventions can promote weight loss and delay the onset of diabetes. ${ }^{65-67} \mathrm{~A}$ digital DPP has a greater chance of scaling and reaching this population than a resourceconstrained system that has a greater dependence on challenging face-to-face deployments in the community. ${ }^{68,69}$

\section{Access to Digitally Mediated Diabetes Care}

The case for digitally mediated care builds when we consider the scarcity of diabetes care providers together with the growing need of $>30$ million people in the United States living with diabetes. ${ }^{70}$ There are less than 20,000 certified diabetes educators and no more than 5000-6000 endocrinologists in the United States. ${ }^{71-73}$ A digital health intervention not only facilitates the needed structure, but also creates virtual access to care providers. ${ }^{74-78}$ Much of this care can be better facilitated with "just-in-time" asynchronous messaging than the less efficient and less timely face-to-face encounters that our current system is predicated upon. ${ }^{79-81}$ The balance between coaching and education provided by the app and by a live educator continues to evolve. There are examples that much of what a dietician can provide can be delivered digitally and be well received. ${ }^{82}$

There are also a number of other categories of apps that would be potentially beneficial for those living with diabetes but are not explicitly diabetes apps. These include the rich ecosystem of general health and wellness apps for weight loss, exercise, and mental health. There is no suggestion that diabetes apps can, or even should, encompass all aspects of general health and wellness into a single app. However, because so much of diabetes care involves diet and the effect of physical activity, it is not surprising to see features that support these aspects commonly supported in diabetes apps.

But is there the professional and cultural readiness required to begin a new era of the prescribing and use of digital therapeutics? ${ }^{83}$ There are many vulnerable people in the T2D community who perhaps will never be suited for digital therapeutics as an adjunctive therapy or to facilitate their care virtually. ${ }^{84}$ Personal human interaction will continue to play an important part in the care for millions of people living with diabetes, no matter the progress and sophistication of these digital services. What these technologies will provide, however, is the human capacity to deal with the higher need vulnerable people for whom access to timely care is an issue. Moreover, it will provide choice for an increasingly diverse population that seeks options on the form, and delivery, of their care.

The experiences of both patient and provider will no doubt change as the models for digitally-mediated diabetes care evolve from this first decade of iteration. But there is little doubt that the system needs to embrace digital alternatives to facilitate implementation of care models that improve outcomes, address psychosocial needs, and enhance quality of life among the growing diabetes population.

\section{Acknowledgments}

The author acknowledges the support of the Wolfond Chair in Digital Health at the University Health Network. In addition, the author is grateful to Chris Parkin of CGParkin Communications, Inc. for his thoughtful editorial review of this article. Roche Diabetes Care provided funding for the development of this study.

\section{Author Disclosure Statement}

No competing financial interests exist.

\section{References}

1. Singh K, Drouin K, Newmark LP, et al.: Many mobile health apps target high-need, high-cost populations, but gaps remain. Health Aff 2016;35:2310-2318.

2. Smartphone Apps for Diabetes Management: Diabetes Forecast. www.diabetesforecast.org/2017/mar-apr/diabetesapplications.html (accessed March 31, 2019).

3. Katz D, Dalton N, Price B: Diabetes apps \& long-term daily adoption. In: 8th International Conference on Advanced Technologies \& Treatments for Diabetes. ATTD 2015, Paris, France-February 18-21, 2015.

4. Krebs P, Duncan DT: Health app use among US mobile phone owners: a national survey. JMIR Mhealth Uhealth 2015;3:e101.

5. Wu Y, Yao X, Vespasiani G, et al.: Mobile app-based interventions to support diabetes self-management: a systematic review of randomized controlled trials to identify functions associated with glycemic efficacy. JMIR Mhealth Uhealth 2017;5:e35.

6. Kitsiou S, Paré G, Jaana M, Gerber B: Effectiveness of mHealth interventions for patients with diabetes: an overview of systematic reviews. PLoS One 2017;12:e0173160.

7. Greenwood DA, Gee PM, Fatkin KJ, Peeples M: A systematic review of reviews evaluating technology-enabled diabetes self-management education and support. J Diabetes Sci Technol 2017;11:1015-1027.

8. Bonoto BC, de Araújo VE, Godói IP, et al.: Efficacy of mobile apps to support the care of patients with diabetes mellitus: a systematic review and meta-analysis of randomized controlled trials. JMIR Mhealth Uhealth 2017;5: e4.

9. Fu H, McMahon SK, Gross CR, et al.: Usability and clinical efficacy of diabetes mobile applications for adults with type 2 diabetes: a systematic review. Diabetes Res Clin Pract 2017;131:70-81.

10. Hou C, Carter B, Hewitt J, et al.: Do mobile phone applications improve glycemic control (HbA1c) in the selfmanagement of diabetes? A systematic review, meta-analysis, 
and GRADE of 14 randomized trials. Diabetes Care 2016;39: 2089-2095.

11. Thies K, Anderson D, Cramer B: Lack of adoption of a mobile app to support patient self-management of diabetes and hypertension in a Federally Qualified Health Center: interview analysis of staff and patients in a failed randomized trial. JMIR Hum Factors 2017;4:e24.

12. Isaković M, Sedlar U, Volk M, Bešter J: Usability pitfalls of diabetes mHealth apps for the elderly. J Diabetes Res 2016;2016:1604609.

13. Izahar S, Lean QY, Hameed MA, et al.: Content analysis of mobile health applications on diabetes mellitus. Front Endocrinol 2017;8:318.

14. Beck RW, Bergenstal RM, Riddlesworth TD, Kollman $\mathrm{C}$ : The association of biochemical hypoglycemia with the subsequent risk of a severe hypoglycemic event: analysis of the DCCT data set. Diabetes Technol Ther 2019;21:1-5.

15. Rodbard D: Hypo- and hyperglycemia in relation to the mean, standard deviation, coefficient of variation, and nature of the glucose distribution. Diabetes Technol Ther 2012;14:868-876.

16. Klonoff DC, Kerr D: Overcoming barriers to adoption of digital health tools for diabetes. J Diabetes Sci Technol 2018;12:3-6.

17. Ongwere T, Cantor G, Martin SR, et al.: Too Many Conditions, Too Little Time: Designing Technological Interventions for Patients with Type-2 Diabetes and Discordant Chronic Comorbidities. Retrieved from http://patshih.soic .indiana.edu/publications/Ongwere-MobileDCC-WISH17 .pdf

18. Sarkar U, Karter AJ, Liu JY, et al.: Social disparities in internet patient portal use in diabetes: evidence that the digital divide extends beyond access. J Am Med Inform Assoc 2011;18:318-321.

19. Mayberry LS, Kripalani S, Rothman RL, et al.: Bridging the digital divide in diabetes: family support and implications for health literacy. Diabetes Technol Ther 2011;13:1005-1012.

20. Khosla S, White R, Medina J, et al.: Real world evidence (RWE) - a disruptive innovation or the quiet evolution of medical evidence generation? F1000Res 2018;7:111.

21. Pham Q, Wiljer D, Cafazzo JA: Beyond the randomized controlled trial: a review of alternatives in mHealth clinical trial methods. JMIR Mhealth Uhealth 2016;4:e107.

22. Gawande A: Why Doctors Hate Their Computers. The New Yorker, New York, NY: 1 World Trade Center, 2018.

23. Ehrenfeld JM, Wanderer JP: Technology as friend or foe? Do electronic health records increase burnout? Curr Opin Anaesthesiol 2018;31:357-360.

24. Collier R: Electronic health records contributing to physician burnout. CMAJ 2017;189:E1405-E1406.

25. Schramm W: Digital diabetes self-management: a trilateral serial. J Diabetes Sci Technol 2018;12:709-711.

26. Offringa R, Sheng $\mathrm{T}$, Parks L, et al.: Digital diabetes management application improves glycemic outcomes in people with type 1 and type 2 diabetes. J Diabetes Sci Technol 2018;12:701-708.

27. Wong JC, Neinstein AB, Spindler M, Adi S: A minority of patients with type 1 diabetes routinely downloads and retrospectively reviews device data. Diabetes Technol Ther 2015;17:555-562.

28. Katz DS, Price BA, Holland S, Dalton NS: Data, Data Everywhere, and Still Too Hard to Link. in Proceedings of the 2018 CHI Conference on Human Factors in Computing Systems-CHI'18, April 21-26, 2018, pp. 1-12. Montréal, Canada: ACM Press.

29. Picton PE, Yeung M, Hamming N, et al.: Advancement of the artificial pancreas through the development of interoperability standards. J Diabetes Sci Technol 2013; 7:1066-1070.

30. Silk AD: Diabetes device interoperability for improved diabetes management. J Diabetes Sci Technol 2015;10: 175-177.

31. New Profile Standardizes Data Collection And Measurement Method For Bluetooth Smart Enabled Glucose Monitors: www.bluetooth.com/news/pressreleases/2014/12/09/newprofile-standardizes-data-collection-and-measurement-methodfor-bluetooth-smart-enabled-glucose-monitors (accessed January 13, 2019).

32. Bluetooth Technology: www.bluetooth.com/specifications/ gatt/viewer?attributeXmlFile=org.bluetooth.service.continuous_ glucose_monitoring.xml (accessed January 13, 2019).

33. Neinstein A, Wong J, Look H, et al.: A case study in open source innovation: developing the Tidepool Platform for interoperability in type 1 diabetes management. J Am Med Inform Assoc 2016;23:324-332.

34. Grifantini K: Advances in management technology for diabetes: from personal reminders to digital doctors. IEEE Pulse 2014;5:40-44.

35. Klonoff DC, Zimliki CL, Stevens LA, et al.: Innovations in technology for the treatment of diabetes: clinical development of the artificial pancreas (an Autonomous System). J Diabetes Sci Technol 2011;5:804-826.

36. Lewis D: Setting expectations for successful artificial pancreas/hybrid closed loop/automated insulin delivery adoption. J Diabetes Sci Technol 2018;12:533-534.

37. Farrington C: Hacking diabetes: DIY artificial pancreas systems. Lancet Diabetes Endocrinol 2017;5:332.

38. Health Canada: Draft Guidance Document-Software as a Medical Device (SaMD)—Canada.ca. 2019. www.canada .ca/en/health-canada/services/drugs-health-products/publicinvolvement-consultations/medical-devices/software-medicaldevice-draft-guidance/document.html (accessed February 3, 2019).

39. Center for Devices \& Radiological Health: Software as a Medical Device (SaMD). Retrieved from https://www .fda.gov/medicaldevices/digitalhealth/softwareasamedical device/default.htm

40. Office of the Commissioner: Press AnnouncementsFDA authorizes first fully interoperable continuous glucose monitoring system, streamlines review pathway for similar devices. Retrieved from https://www.fda.gov/ newsevents/newsroom/pressannouncements/ucm602870 .htm

41. Center for Devices \& Radiological Health: Digital Health Software Precertification (Pre-Cert) Program. Retrieved from https://www.fda.gov/medicaldevices/digital health/digitalhealthprecertprogram/default.htm

42. Barnard KD, Ziegler R, Klonoff DC, et al.: Open source closed-loop insulin delivery systems: a clash of cultures or merging of diverse approaches? J Diabetes Sci Technol 2018;12:1223-1226.

43. Desveaux L, Shaw J, Saragosa M, et al.: A mobile app to improve self-management of individuals with type 2 diabetes: qualitative realist evaluation. J Med Internet Res 2018;20:e81. 
44. Pal K, Dack C, Ross J, et al.: Digital health interventions for adults with type 2 diabetes: qualitative study of patient perspectives on diabetes self-management education and support. J Med Internet Res 2018;20:e40.

45. Russo GT, Scavini M, Acmet E, et al.: The burden of structured self-monitoring of blood glucose on diabetesspecific quality of life and locus of control in patients with noninsulin-treated type 2 diabetes: the PRISMA study. Diabetes Technol Ther 2016;18:421-428.

46. Malanda UL, Bot SD, Nijpels G: Self-monitoring of blood glucose in noninsulin-using type 2 diabetic patients: it is time to face the evidence. Diabetes Care 2013;36: 176-178.

47. Dean HJ. Self-monitoring of blood glucose levels in persons with type 2 diabetes not requiring insulin: routine use is not recommended. Canadian J Diabetes 2011;35:19-20.

48. BBC News: Diabetics' Test Strips "restricted." BBC, London, United Kingdom, 2013.

49. Boyle T: Ontario Quietly Cuts Funding for Diabetics' Blood-Sugar Test Strips. The Toronto Star, 1 Yonge Street Toronto, Canada, 2013.

50. Young LA, Buse JB, Weaver MA, et al.: Glucose selfmonitoring in non-insulin-treated patients with type 2 diabetes in primary care settings: a randomized trial. JAMA Intern Med 2017;177:920-929.

51. Heneghan C: Is It the End for Type 2 Diabetes Monitoring? | BMJ EBM Spotlight. BMJ EBM Spotlight, 2017. https:// blogs.bmj.com/bmjebmspotlight/2017/10/19/is-this-the-end-ofmonitoring-in-type-2-diabetes/ (accessed January 26, 2019).

52. St John A, Davis WA, Price CP, Davis TME: The value of self-monitoring of blood glucose: a review of recent evidence. J Diabetes Complications 2010;24:129-141.

53. Speight J, Browne JL, Furler J: Challenging evidence and assumptions: is there a role for self-monitoring of blood glucose in people with type 2 diabetes not using insulin? Curr Med Res Opin 2013;29:161-168.

54. Hall H, Perelman D, Breschi A, et al.: Glucotypes reveal new patterns of glucose dysregulation. PLoS Biol 2018;16: e2005143.

55. Kirscht JP: The health belief model and predictions of health actions. In: Gochman DS, ed. Health Behavior. Springer, 1998, pp. 27-41.

56. Dlugasch LB, Ugarriza DN: Self-monitoring of blood glucose experiences of adults with type 2 diabetes. J Am Assoc Nurse Pract 2014;26:323-329.

57. Polonsky WH, Fisher L: Self-monitoring of blood glucose in noninsulin-using type 2 diabetic patients: right answer, but wrong question: self-monitoring of blood glucose can be clinically valuable for noninsulin users. Diabetes Care 2013;36:179-182.

58. Polonsky WH, Fisher L, Schikman CH, et al.: Structured self-monitoring of blood glucose significantly reduces A1C levels in poorly controlled, noninsulin-treated type 2 diabetes: results from the Structured Testing Program study. Diabetes Care 2011;34:262-267.

59. Rodbard HW, Schnell O, Unger J, et al.: Use of an automated decision support tool optimizes clinicians' ability to interpret and appropriately respond to structured selfmonitoring of blood glucose data. Diabetes Care 2012;35: 693-698.

60. Parkin CG, Buskirk A, Hinnen DA, Axel-Schweitzer M: Results that matter: structured vs. unstructured selfmonitoring of blood glucose in type 2 diabetes. Diabetes Res Clin Pract 2012;97:6-15.
61. Kerr D: Self-monitoring of blood glucose and type 2 diabetes: new tricks for the old dog? J Diabetes Sci Technol 2011;5:209-211.

62. Polonsky WH, Fisher L, Hessler D, Edelman SV: A survey of blood glucose monitoring in patients with type 2 diabetes: are recommendations from health care professionals being followed? Curr Med Res Opin 2011;27 Suppl 3: 31-37.

63. Grady M, Cameron H, Levy BL, Katz LB: Remote health consultations supported by a diabetes management web application with a new glucose meter demonstrates improved glycemic control. J Diabetes Sci Technol 2016;10: 737-743.

64. LeFevre ML, U.S. Preventive Services Task Force. Behavioral counseling to promote a healthful diet and physical activity for cardiovascular disease prevention in adults with cardiovascular risk factors: U.S. Preventive Services Task Force Recommendation Statement. Ann Intern Med 2014; 161:587-593.

65. Sepah SC, Jiang L, Peters AL: Translating the diabetes prevention program into an online social network: validation against CDC standards. Diabetes Educ 2014;40:435443.

66. Sepah SC, Jiang L, Peters AL: Long-term outcomes of a Web-based diabetes prevention program: 2-year results of a single-arm longitudinal study. J Med Internet Res 2015;17: e92.

67. Joiner KL, Nam S, Whittemore R. Lifestyle interventions based on the diabetes prevention program delivered via eHealth: a systematic review and meta-analysis. Prev Med 2017;100:194-207.

68. Ackermann RT, Finch EA, Brizendine E, et al.: Translating the diabetes prevention program into the community. The DEPLOY Pilot Study. Am J Prev Med 2008;35: 357-363.

69. Ackermann RT, Marrero DG: Adapting the Diabetes Prevention Program lifestyle intervention for delivery in the community: the YMCA model. Diabetes Educ 2007;33:69, 74-75, 77-78.

70. CDC Press Releases: CDC. 2017. www.cdc.gov/media/ releases/2017/p0718-diabetes-report.html (accessed January 26, 2019).

71. 2016 Count of CDEs by State and Other StatisticsGeneral News-News | NCBDE. www.ncbde.org/2016count-of-cdes-by-state-and-other-statistics/?pg=3 (accessed January 26, 2019).

72. A Shortage of Diabetes Doctors: Diabetes Forecast. www .diabetesforecast.org/2014/09-sep/a-shortage-of-diabetesdoctors.html (accessed January 26, 2019).

73. Vigersky RA, Fish L, Hogan P, et al.: The clinical endocrinology workforce: current status and future projections of supply and demand. J Clin Endocrinol Metab 2014;99: 3112-3121.

74. Quinn CC, Butler EC, Swasey KK, et al.: Mobile diabetes intervention study of patient engagement and impact on blood glucose: mixed methods analysis. JMIR Mhealth Uhealth 2018;6:e31.

75. Kumar S, Moseson H, Uppal J, Juusola JL: A diabetes mobile app with in-app coaching from a certified diabetes educator reduces A1C for individuals with type 2 diabetes. Diabetes Educ 2018;44:226-236.

76. Brandell B, Ford C: Diabetes professionals must seize the opportunity in mobile health. J Diabetes Sci Technol 2013; 7:1616-1620. 
77. Kirwan M, Vandelanotte C, Fenning A, Duncan MJ: Diabetes self-management smartphone application for adults with type 1 diabetes: randomized controlled trial. J Med Internet Res 2013;15:e235.

78. Goyal S, Nunn CA, Rotondi M, et al.: A mobile app for the self-management of type 1 diabetes among adolescents: a randomized controlled trial. JMIR Mhealth Uhealth 2017;5: e82.

79. Saffari M, Ghanizadeh G, Koenig HG: Health education via mobile text messaging for glycemic control in adults with type 2 diabetes: a systematic review and meta-analysis. Prim Care Diabetes 2014;8:275-285.

80. Goodarzi M, Ebrahimzadeh I, Rabi A, et al.: Impact of distance education via mobile phone text messaging on knowledge, attitude, practice and self efficacy of patients with type 2 diabetes mellitus in Iran. J Diabetes Metab Disord 2012;11:10.

81. Blevins T: Value and utility of self-monitoring of blood glucose in non-insulin-treated patients with type 2 diabetes mellitus. Postgrad Med 2013;125:191-204.

82. Farfan CC, Axelrod C, Frase DL, et al.: Digital dietitianpilot study of a novel smartphone application. Diabetes 2018;67:767-P.
83. Ferguson C, Hickman L, Wright R, et al.: Preparing nurses to be prescribers of digital therapeutics. Contemp Nurse 2018;54:345-349.

84. Mathiesen AS, Thomsen T, Jensen T, et al.: The influence of diabetes distress on digital interventions for diabetes management in vulnerable people with type 2 diabetes: a qualitative study of patient perspectives. J Clin Transl Endocrinol 2017;9:41-47.

Address correspondence to: Joseph A. Cafazzo, PhD, PEng Centre for Global eHealth Innovation Wolfond Chair in Digital Health Techna Institute

Toronto General Hospital University Health Network 190 Elizabeth Street, 4th Floor 4 Fraser Elliott Building Toronto M5G2C4

Ontario

Canada

E-mail: joe.cafazzo@uhn.ca 